\title{
Electron Cyclotron Heating in Tokamaks
}

\author{
Owen Eldridge \\ Won Namkung \\ Alan C. England
}

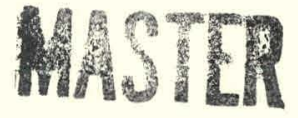

OAK RIDGE NATIONAL LABORATORY OPERATED BY UNION CARBIDE CORPORATION · FOR THE DEPARTMENT OF ENERGY 


\section{DISCLAIMER}

This report was prepared as an account of work sponsored by an agency of the United States Government. Neither the United States Government nor any agency Thereof, nor any of their employees, makes any warranty, express or implied, or assumes any legal liability or responsibility for the accuracy, completeness, or usefulness of any information, apparatus, product, or process disclosed, or represents that its use would not infringe privately owned rights. Reference herein to any specific commercial product, process, or service by trade name, trademark, manufacturer, or otherwise does not necessarily constitute or imply its endorsement, recommendation, or favoring by the United States Government or any agency thereof. The views and opinions of authors expressed herein do not necessarily state or reflect those of the United States Government or any agency thereof. 


\section{DISCLAIMER}

Portions of this document may be illegible in electronic image products. Images are produced from the best available original document. 
Printed in the United States of America. Available from National Technical Information Service

U.S. Department of Commerce

5285 Port Royal Road, Springfield, Virginia 22161

Price: Printed Copy $\$ 4.50$; Microfiche $\$ 3.00$

This report was prepared as an account of work sponsored by an agency of the United States Government. Neither the United States Government nor any agency thereof, nor any of their employees, contractors, subcontractors, or their employees, makes any warranty, express or implied, nor assumes any legal liability or responsibility for any third party's use or the results of such use of any information, apparatus, product or process disclosed in this report, nor represents that its use by such third party would not infringe privately owned rights. 
Contract No. W-7405-eng-26

FUSION ENERGY DIVISION

ELECTRON CYCLOTRON HEATING IN TOKAMAKS

This report was prepared as an account of work sponsored by tho United States Covernment. Neillier the United States nor the United Siates Department of Buergy, nor sny of their employees, noz any of their contractors, subcontractors, or theis employees, makes any warranty, express or implied, or assumes any legal liabilty or responsibutity for the accuracy, completeness or ucofulness of any inforilustiunt, apparatus, product or process disclosed, or represents that its use would not infringe privately owned rights.

\author{
Owen Eldridge
}

Won Namkung

The University of Tennessee, Knoxville, Tennessee 37916 and

Oak Ridge National Laboratory, Oak Ridge, Tennessee 37830

Alan C. England

Oak Ridge National Laboratory, Oak Ridge, Tennessee 37830

NOTICE This document contains information of a preliminary nature. It is subject to revision or correction and therefore does not represent a final report.

Date Pub1ished - November 1977.

Prepared by the

OAK RIDGE NATIIONAL LABORATORY

Oak Ridge, Tennessee 37830

operated by

UNION CARBIDE CORPORATION

for the

DEPARTMENT OF ENERGY 
THIS PAGE

\section{WAS INTENTIONALLY LEFT BLANK}


CONTENTS

ABSTRACT . . . . . . . . . . . . . . . . . . . . 1

I. INTRODUCTION ................... 2

II. DISPERSION, PROPAGATION, AND POLARIZATION . . . . . . 4

III. ELECTRON HEATING RATES . . . . . . . . . . . . . 11

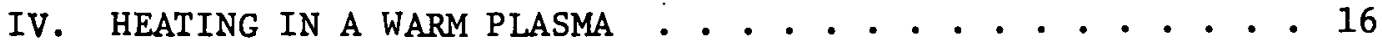

A. The heating rate . . . . . . . . . . . . 17

B. Wave attenuation ............. 18

V. RESULTS AND CONCLUSIONS . . . . . . . . . . . . 22

A. Almost perpendicular incidence . . . . . . . . 22

B. Fractional absorption... . . . . . . . . . 22

C. Waveguide excitation ............. . 24

D. Spatial dependence . . . . . . . . . . . 27

E. Conclusions . . . . . . . . . . . . . 27 


\section{ABSTRACT}

Tokamaks may be efficiently. heated at electron cyclotron resonance by launching of the extraordinary wave from the inside of the torus with a simple waveguide aperture. For typical tokamak parameters, $90 \%$ of the. incident energy is absorbed in one traversal of the resonant surface. There is an effective maximum density for linear heating at the point where the plasma frequency is equal to the cyclotron frequency. The bulk of the plasma electrons is heated, increasing the perpendicular energy with no tendency to accelerate a high energy tail of the velocity distribution. The ordinary wave may be launched from outside the torus with somewhat smaller heating efficiency. Heating rates and velocity diffusion coefficlents are presented. 


\section{INTRODUCTION}

In a series of experiments on the TM-3 tokamak at the I. V. Kurchatov Institute of Atomic Energy in Moscow, Alikaev and coworkers have shown that linear electron cyclotron heating is an effective means of heating electrons in high density plasmas.1,2 They obtained evidence for effective absorption of the incident microwave power over a wide range of plasma parameters, Including experiments with no upper hybrid resonance in the plasma. In addition, very little electron heating was observed when the upper hybrid resonance was located within the plasma volume but the electron cyclotron resonance was not. The temperature increase obtained with cyclotron heating was comparable to that obtained with ohmic heating. The entire distribution of electrons was heated with no observable acceleration of a hot electron tail.

In contrast, experiments on the Spherator at the Princeton Plasma Phystcs Laboratory ${ }^{3}$ indicated that a nonlinear interaction was responsible for heating near the upper hybrid resonance. This interaction had a threshold in incident power and produced the rypical sideband spectrum of parametric instabilities. The plasma density was high; that is, the plasma frequency, $w_{p}=\left(4 \pi n e^{2 / m}\right)^{1 / 2}$, was about equal to the electron cyclotron frequency, $\Omega=\mathrm{eB} / \mathrm{mc}$. The electron temperature was very low, $\mathrm{T} \approx 1 \mathrm{eV}$, in the Spherator experiment. From these and other similar experiments with high density plasmas, one is led to a tentative conclusion: nonlinear interactions occur near the upper hybrid resonance when the electron temperature is low, and linear absorption occurs at cyclotron resonance when the electron temperature is initially high. This is also the conclusion of the present calculation. 
For low density plasmas, electron cyclotron heating has been successfully used for many years. In the ELMO mirror machine and the ELMO Bumpy Torus (EBT) at Oak Ridge National Laboratory (ORNL), electron temperatures of $T \simeq 700 \mathrm{keV}$ have been achfeved in steady state with quite modest power inputs. ${ }^{4-6}$ The linear theories of cyclotron heating at low density have accounted quantitatively for the observed heating rates. ${ }^{7,8}$ In these theories, the dispersion of the incident wave was neglected and the electric fields in the plasma were taken to be homogeneous and isotropic. These assumptions are reasonable for large multimode cavities containing low density plasma, with only a fraction of the wave energy absorbed during each traversal of a resonant surface by a wave, but are not valid at high densities.

In the present calculation, these faults of the low density theories are corrected; the overall treatment is similar in that the emphasis is on electron heating rather than on wave damping. In Sect. II, wave dispersion and polarization are discussed in cold plasma theory. Two results are particularly relevant. First, the extraordinary wave must be launched from the inside of the torus, while the ordinary wave may be launched from any point. Second, the linear combination of electric fields that acce1erates electrons,'which is $E_{x}-i E_{y}$ in a local coordinate system with the static magnetic fiel. in the $\mathrm{z}$ direction, vanishes at cyclotron resonance. The conclusion is that linear cyclotron heating can only occur with finite temperatures that will broaden the spatial cyclotron resonance or at low density .

In Sect. III, a Fokker-Planck equation is presented for the electron velocity distribution driven by the external fields. The fields are 
evaluated from the warm plasma dispersion. The electron heating is found to be effective for the entire velocity distribution, despite an essentially linear dependence on temperature.

In Sect. IV, numerical results are given for waves launched from a waveguide aperture. Heating rates in a tokamak are found to depend essentially on the ratio $\omega_{p} / \Omega$, on the ratio of wavelength to the major radius of the torus, and on the electron temperature. The heating becomes very small in the parameter range where $\omega_{\mathrm{p}} / \Omega>1$, although the extraordinary wave propagates for all densities such that $\omega_{\mathrm{p}} / \Omega<2^{1 / 2}$.

II. DISPERSION, PROPAGATION, AND POLARIZATION

In a plasma the propagation of electromagnetic waves is determined by the equation

$$
\vec{i} \times(\vec{u} \times \vec{E})+\vec{t} \cdot \vec{E}=0 \text {, }
$$

where $\vec{n}=\vec{k} c / \omega$ is the vector index of refraction. With the static magnetic field in the $z$ direction, the nonzero components of the dielectric tensor in a cold electron plasma are

$$
\begin{aligned}
& \varepsilon_{x x}=\varepsilon_{y y}=1-\frac{\omega_{p}^{2}}{\omega^{2}-\Omega^{2}}, \\
& \varepsilon_{x y}=-\varepsilon_{y x}=i \frac{\omega_{p}^{2}}{\omega^{2}-\Omega^{2}} \frac{\Omega}{\omega},
\end{aligned}
$$

and

$$
\varepsilon_{z z}=1-\frac{\omega_{p}^{2}}{\omega^{2}} .
$$

The ion contribution to dispersion is negligible in the frequency range near cyclotron resonance. The absolute value of the electron cyclotron 
frequency is $\Omega$. The equation is to be interpreted as the first term of an eikonal expansion, with $\vec{n}, \vec{E}$, and $\vec{\varepsilon}$ taken as slowly varying functions of space, while the frequency is real and constant.

The two solutions of the determinental equation, the extraordinary ( $x$ ) mode and the ordinary ( 0 ) mode, have properties best displayed on a Clemnow-Mullaly-Allis (CMA) diagram, ${ }^{9}$ reproduced in Fig. 1 . For the present analysis the salient points are:

(1) The $X$ wave may enter the inside edge of a plasma in a toroidal magnetic field (a point $\omega_{\mathrm{p}}^{2} / \omega^{2}=0, \Omega^{2} / \omega^{2}>1$ ) and propagate directly through cyclotron resonance (the line $\omega=\Omega$ ) to upper hybrid resonance [the line $\omega=\left(\omega_{p}^{2}+\Omega^{2}\right)^{1 / 2}$ ]. This preferred path is shown by an arrow in Fig. 1. Cyclotron resonance may always be reached for local densities such that $\omega_{\mathrm{p}}^{2} \leqslant 2 \Omega^{2}$, which is the high density cutoff for the $\mathrm{X}$ mode.

(2) When launched from the outside of a torus (a point $\omega_{\mathrm{p}}^{2} / \omega^{2}=0$, $\left.\Omega^{2} / \omega^{2}<1\right)$, the $\mathrm{X}$ wave meets a cutoff before reaching upper hybrid resonance or cyclotron resonance.

(3) The 0 wave meets no plasma cutoffs and only cyclotron resonance in the entire region with $\omega_{\mathrm{p}}^{2} / \omega^{2}<1$; this wave may be launched from any point on the plasma surface.

Figure 2 shows a cross section of a tokamak with a toroidal magnetic field and a parabolic density profile. The locations of the upper hybrid resonant surface, the cutoff surface for the $\mathrm{X}$ mode, and the cyclotron resonant surface are shown.

In addition, the cold plasma dispersion relation may be used to show directly that: 


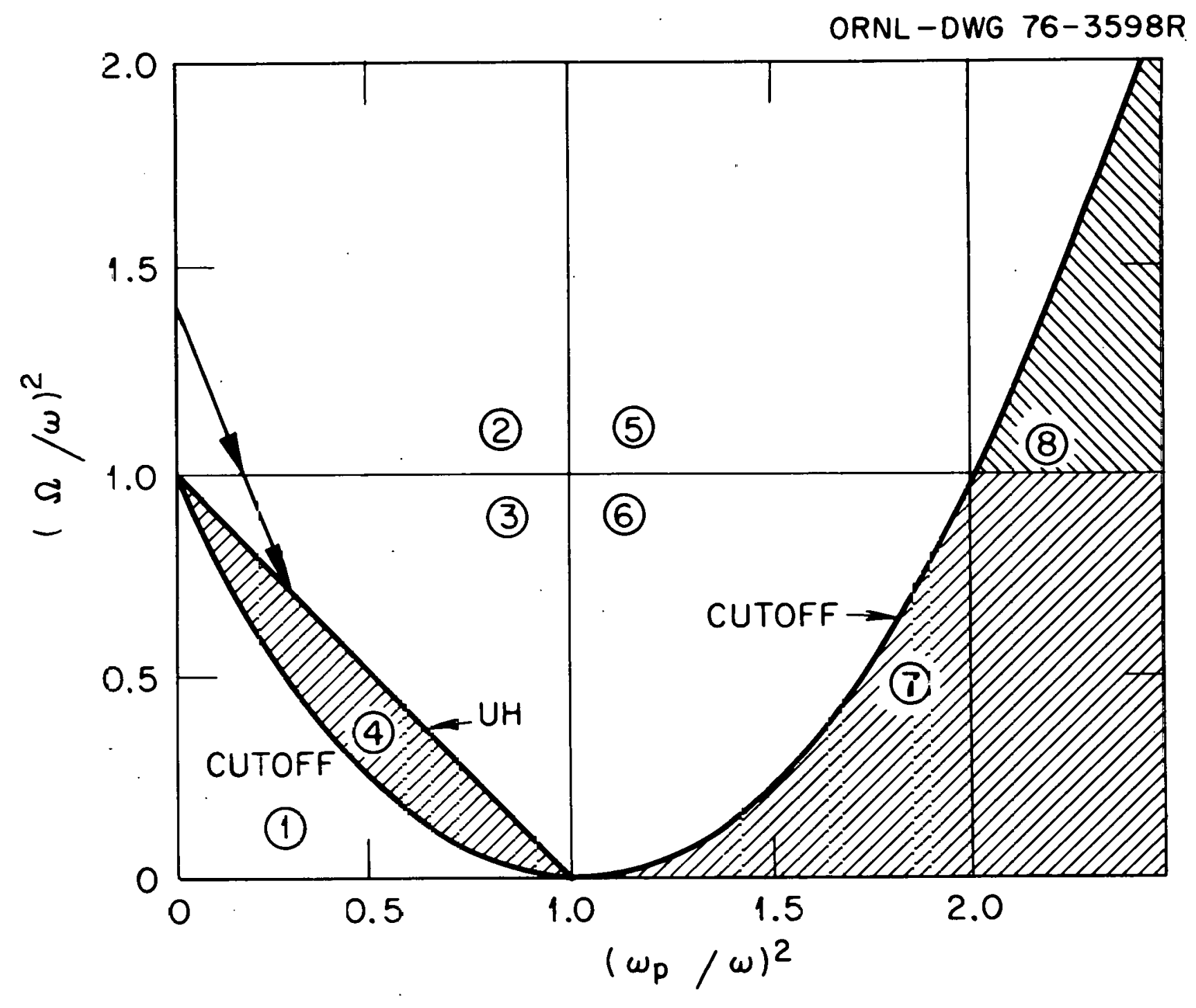

Fig. i. 
ORNL-OWG 76-3597

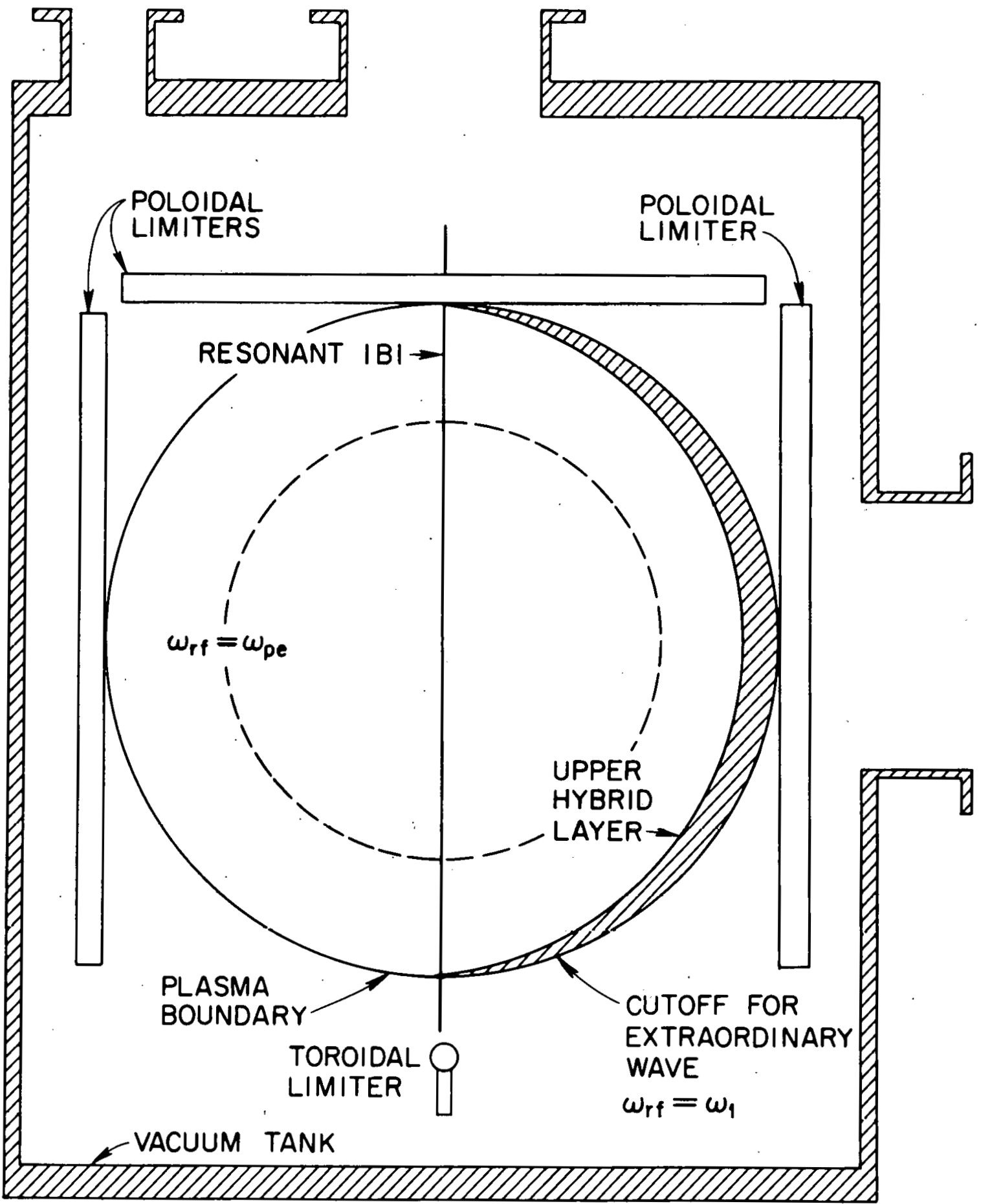

Fig. 2. 
(4) At cyclotron resonance $(\omega=\Omega)$, the dielectric tensor components $\varepsilon_{\mathrm{xx}}, \varepsilon_{\mathrm{xy}}, \varepsilon_{\mathrm{yy}}$, and $\varepsilon_{\mathrm{yx}}$ become infinite, but the index of refraction and the electric fields remain finite and are smoothly varying through this surface.

(5) The electric field combination $E^{-}=E_{x}-1 E_{y}$ vanishes at cyclotron resonance in a cold, dense plasma, 10 because from Eq. (1) one finds that $\left.\left(E_{x}-i E_{y}\right) \omega_{p}^{2} /(\omega)^{2}-\Omega^{2}\right)$ is finite at this surface. This field combination accelerates electrons at cyclotron resonance, so cyclotron heating can only occur when the cyclotron resonance is broadened by finite electron temperature. This effect is analyzed in Sec. IV. These conclusions are 1llustrated in Fig. 3, which shows the electric field components and the index of refraction $n_{x}$ for the $X$ wave launched into a planestratified plasma with a magnetic field decreasing in the $x$ direction, $\mathrm{B}_{z}=\mathrm{B}_{0} \mathrm{R}_{0} /\left(\mathrm{R}_{0}+\mathrm{x}\right)$. The plasma density is parabolic about $\mathrm{x}=0$. This configuration approximates the principal plane of a tokamak of major radius $R_{Q}$. In this plane the parallel index of refraction $n_{z}$ is constant. Field ratios are determined trom kq. (1), and field magnitudes dre dectemined by requiring that the component of the Poynting vector in the $x$ direction be constant, with absorption neglected. Rotational transform is not included in this model.

(6) The wave energy does not propagate very far along the static magnetic field lincs before crossing cyclutrun susulance. Several ray, or Poynting vector, trajectories in the $x-z$ plane for the $X$ wave are plotted in Fig. 4. The central density is less than the critical density, $\omega_{\mathrm{po}}^{2}<$ $\omega^{2}$. The ray reaches the resonant surface at $x=0$ within a short axial distance even when the wave is launched at grazing incidence with $n_{z}=1$. 
ORNL/DWG / FED - 77593

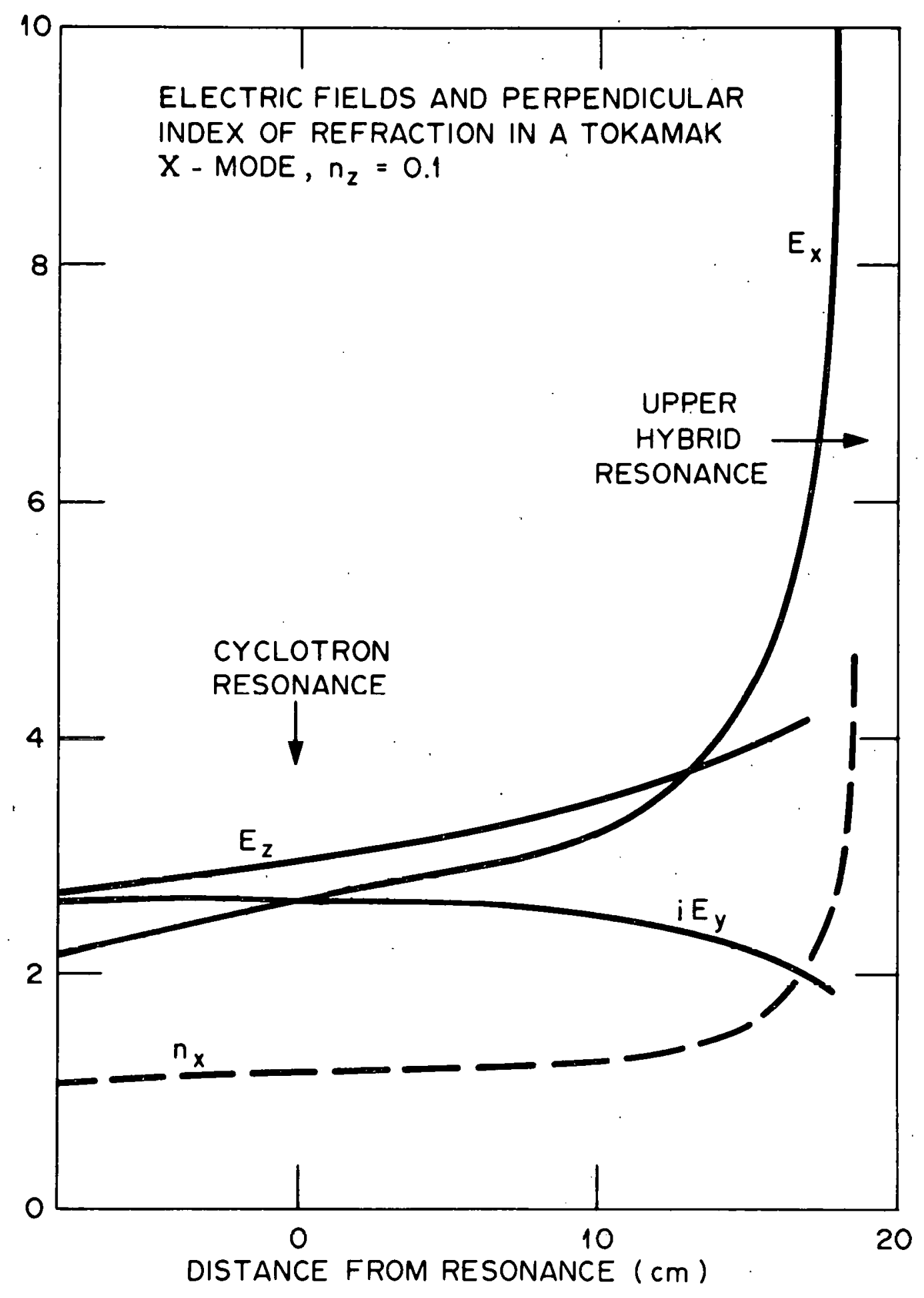

Fig. 3 . 


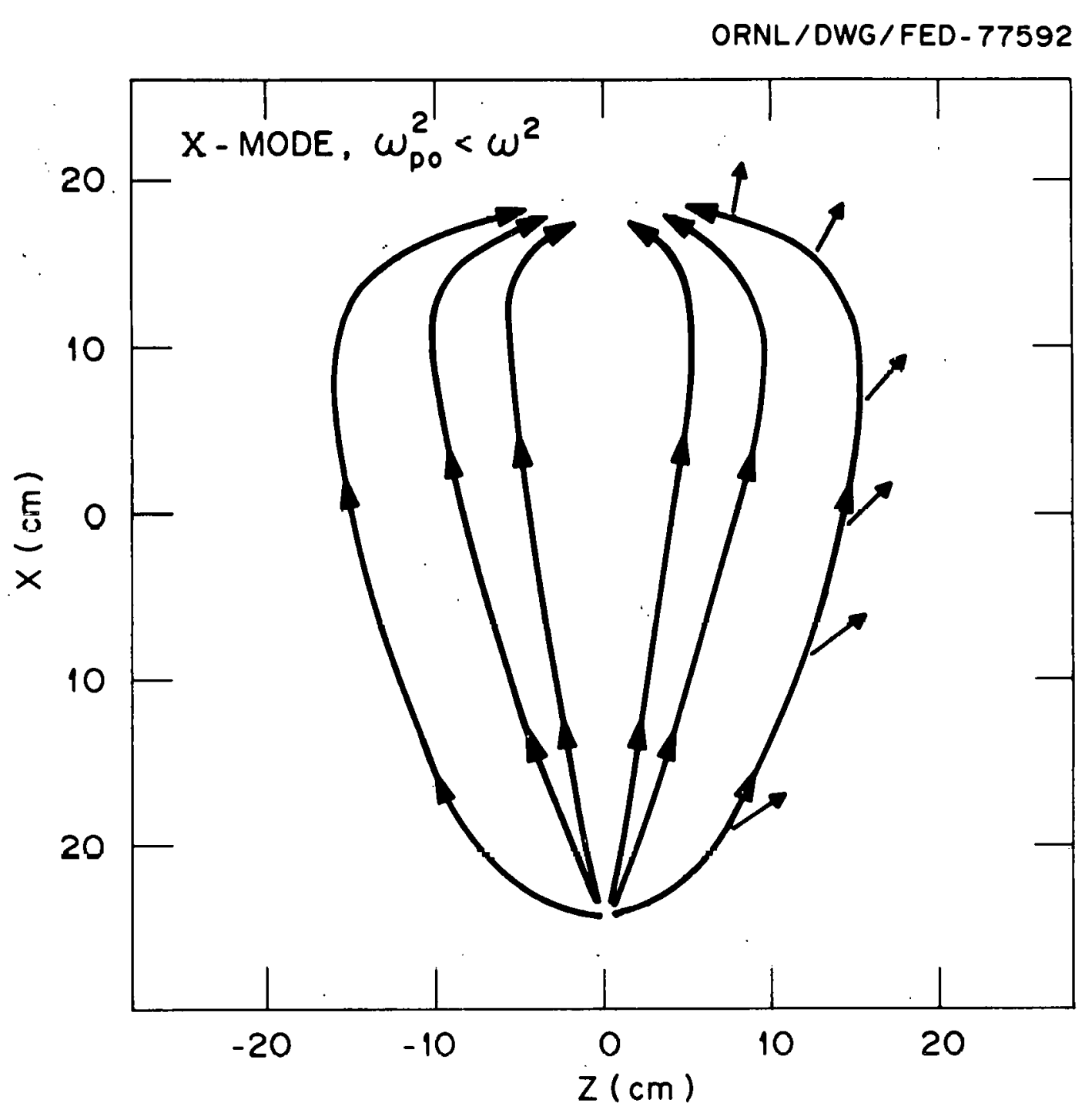

Fig. 4. 
The direction of $\vec{k}$ or the wave velocity is indicated by the short arrows. The wave vector is perpendicular to the ray vector at the upper hybrid resonance. A focusing effect is seen with the rays which were launched paralel to B making an antiparallel approach to the upper hybrid surface.

(7) For densities above the critical density, some $\mathrm{X}$ wave energy is reflected, with rays near perpendicular incidence propagating to the center. The case with $\omega_{\text {po }}^{2}>\omega^{2}$ is illustrated in Fig. 5 for the $X$ wave. This ray tracing technique has also been applied to the 0 wave. As expected, the rays always propagate through cyclotron resonance when $\omega_{\text {po }}^{2}<\omega^{2}$. A three-dimensional analysis of the ray trajectories in tokamak geometry has been made and agrees quantitatively with these results. 11

\section{ELECTRON HEATING RATES}

A quasilinear equation for the electron velocity distribution driven by external electromagnetic fields may be derived by iteration of the Vlasov equation. ${ }^{2}$ This equation has the Fokker-Planck form

$$
\begin{aligned}
\frac{\partial F}{\partial t} & =\pi\left(\frac{e}{2 m \omega}\right)^{2} \sum_{\text {modes }} \sum_{N=-\infty}^{w}\left\{\frac{1}{v_{\perp}} \frac{\partial}{\partial v_{\perp}}\right. \\
& \times\left[N \Omega|A|^{2} \delta\left(\omega-N \Omega-k_{z} v_{z}\right)\left(\frac{N S}{v_{\perp}} \frac{\partial F}{\partial v_{\perp}}+k_{z} \frac{\partial F}{\partial v_{z}}\right)\right] \\
& \left.+\frac{\partial}{\partial v_{z}}\left[k_{z}|A|^{2} \delta\left(\omega-N \Omega-k_{z} v_{z}\right)\left(\frac{N \Omega}{v_{\perp}} \frac{\partial F}{\partial v_{\perp}}+k_{z} \frac{\partial F}{\partial v_{z}}\right)\right]\right\},
\end{aligned}
$$

with

$$
A=v_{1} E^{-} e^{i \alpha_{J_{N}-1}^{\prime}}+v_{1} E^{+} e^{-i \alpha} J_{N+1}+2 v_{z} E_{z} J_{N}
$$

The argument of the Bessel functions, $\mathrm{J}_{\mathrm{N}}$, is $\mathrm{k}_{\perp} \mathrm{v}_{1} / \Omega$; $\alpha$ is the azimuthal angle of the $\vec{k}$ vector; and $E^{ \pm}=E_{x} \pm i E_{y}$. The electron cyclotron 


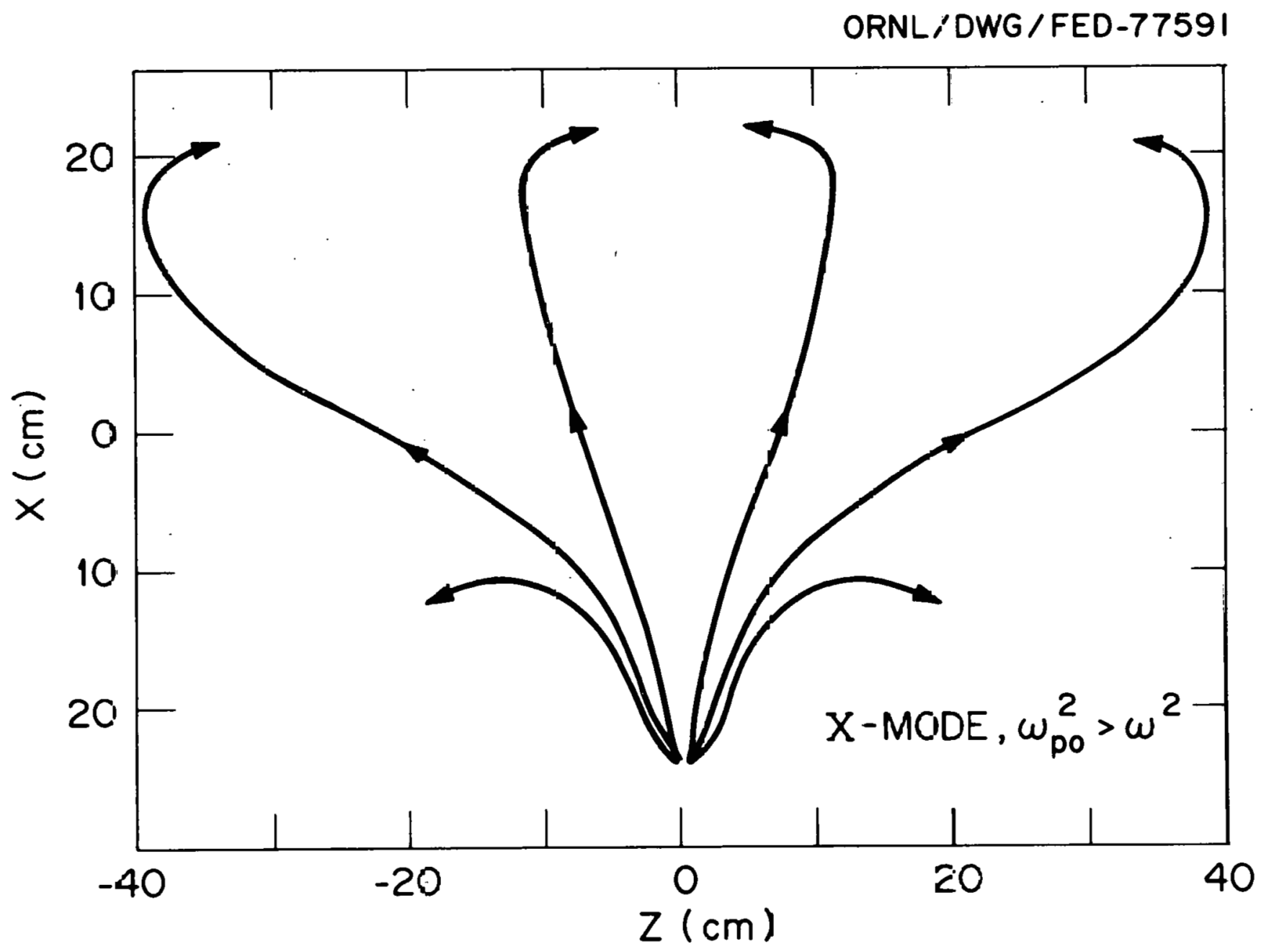

N

Fig. 5. 
frequency $\Omega$ is positive, and terms with negative $N$ and negative $\omega$ are to be included.

The distribution $F$ may vary slowly in space and time, but on a time scale much longer than the cyclotron period. The interaction occurs on a resonant surface, with the exact position determined by the Doppler shift from parallel motion. The phase of electrons passing through this surface is taken to be random. This random element may be the result of electrons drifting through resonance in a collisionless plasma or the result of collisions. For example, in a toroidal magnetic field without rotational transform, an electron drifts on a surface of constant magnetic field and accelerates continuously. However, a collisional randomization is sufficient to produce velocity diffusion at the rate of Eq. (3).

Strictly, the orbits of electrons should include the slow drift velocity and the rotational transform of the magnetic field. The delta function in Eq. (3) should have a term $\vec{k} \cdot \vec{v}_{d}$ instead of $k_{z} v_{z}$. However, because the sum over modes of the microwave field contains an integral over a broad spectrum in $k_{z}$, these effects are completely negligible. In a tokamak, the energy gained by electrons on a millisecond time scale is spread over the drift surface on a microsecond time scale, so that the energy may be considered to be deposited uniformly on the drift surface. For these frequencies, there is little distinction between trapped and untrapped electrons in the heating process. In a collisionless plasma, the velocity diffusion will affect the number and the velocity distribution of the trapped electrons, but this aspect of the problem is not treated here. Cyclotron heating rates are comparable to ohmic heating rates, and in present-day tokamaks collision frequencies are large enough to maintain a 
Maxwellian electron distribution with a local temperature $T(\vec{r})$ and density $\mathrm{n}(\overrightarrow{\mathrm{r}})$. The perpendicular wavelengths are always much larger than the electron cyclotron radius and smaller than scale lengths, so a small argument expansion may be used for the Bessel functions. A plane-stratified model of the plasma is used in which density, temperature, and the magnetic field vary with $x$ (this is appropriate for radiation in the midplane of the torus). The magnetic field is taken to be

$$
B_{z}=B_{T} R_{o} /\left(R_{0}+x\right)=B_{T}(R-x) / R,
$$

where $B_{T}$ is the toroidal magnetic field at cyclotron resonance and

$$
\Omega(x)=\omega(1=x / \text { R }) .
$$

Inclusion of the rotational transform will only slightly change the shape of the resonant surface.

With these assumptions the temporal evolution of the electron distribution is

$$
\begin{aligned}
\frac{\partial F}{\partial t} & =-\frac{\pi e^{2} n(x)}{4 m \omega T(x)}\left[\frac{m}{2 \pi T(x)}\right]^{3 / 2} \sum_{\operatorname{modes}}\left\{\frac{1}{v_{1}} \frac{\partial}{\partial v_{1}}\right. \\
& \times\left[\Omega(x)|A|^{2} \delta\left(\omega x / R-k_{z} v_{z}\right) \exp \left(-m v^{2} / 2 T\right)\right] \\
& \left.+\frac{\partial}{\partial V_{z}}\left[k_{z}|A|^{2} \delta\left(\omega x / R-k_{z} v_{z}\right) \exp \left(-m v^{2} / 2 T\right)\right]\right\},
\end{aligned}
$$

with

$$
A=v_{\perp}\left[E^{-}+\left(v_{z} k_{x} E_{z} / \Omega\right)\right]
$$

and $\vec{k}=\left(k_{x}, 0, k_{z}\right)$. Only the terms with $N= \pm 1$ are included for both positive and negative frequencies. One concludes directly that the perpendicular heating occurs uniformly for all velocities, while the parallel 
heating rate is proportional to the square of the perpendicular velocity and so is much smaller. Runaway electrons are not selectively accelerated; an electron with large $v_{z}$ is heated at the same rate as one with small $v_{z}$, and the Doppler shift only changes the location of the resonant surface. These heating rates agree with those calculated by more primitive means. ${ }^{8}$

The perpendicular and parallel heating rates per untt volume are found by integrating over the velocities

$$
\frac{d^{2} W_{1}}{d t d V}=\sum_{\text {modes }} \frac{\omega_{P}^{2}}{8} \frac{\Omega}{\omega^{2}} \frac{R}{\Delta} \frac{\exp \left(-x^{2} / 2 \Delta^{2}\right)}{\sqrt{2 \pi}}\left|E^{-}+\frac{n}{n_{z}} \frac{\omega}{\Omega} \frac{x}{R} E_{z}\right|^{2}
$$

and

$$
\frac{d^{2} W_{\|}}{d t d V}=\sum_{\operatorname{modes}} \frac{\omega_{p}^{2}}{8 \omega} \frac{x}{\Delta} \frac{\exp \left(-x^{2} / 2 \Delta^{2}\right)}{\sqrt{2 \pi}}\left|E^{-}+\frac{n}{n_{z}} \frac{\omega}{\Omega} \frac{x}{R} E_{z}\right|^{2},
$$

where the spatial width of the resonance is

$$
\Delta=\left(k_{z}^{2} R^{2} T / m \omega^{2}\right)^{l / 2}=n_{z} R\left(T / m c^{2}\right)^{1 / 2}
$$

For a tokamak with $T=1 \mathrm{keV}$ and $\mathrm{R}=1 \mathrm{~m}$ and for a ray with $\mathrm{n}_{z}=0.5$, one finds $\Delta=2.2 \mathrm{~cm}$, indicating that the energy i.s deposited close to the resonant surface. Equation (10) also indicates that the local parallel heating rate is smaller than the perpendicular heating rate by a factor $x / R$, and it is asymmetric about $x=0$. This asymmetry is produced by the Doppler shift; it is washed out by the poloidal drift motion of electrons in a tokamak. There is also a small axial momentum transfer to electrons, which is proportional to $\mathrm{k}_{z}$ and is ordinarily negligible. 
IV. HEATING IN A WARM PLASMA

Finite temperature effects are included in the dielectric tensor in order to find the electric fields at resonance. Finite cyclotron radius effects are included to first order in the temperature for those terms that are large near the fundamental resonance. The form of the character1stic denominatior, $\omega-\Omega-k_{z} v_{z}=\omega x / R-k_{z} v_{z}$, results in the appearance of the characteristic plasma dispersion function $13 \mathrm{Z}\left(\mathrm{x} / \Delta 2^{1 / 2}\right)$ and 1 ts derivative $Z^{\prime}$ in the dielectric tensor. The appropriate tensor components with $\mathrm{n}_{\mathrm{y}}=0$ are:

$$
\begin{aligned}
& \varepsilon_{x x}=\varepsilon_{y y}=1-\frac{\omega_{p}^{2}}{2 \omega^{2}}\left(\frac{\omega}{\omega+\Omega}-\frac{R}{\Delta 21 / 2} z\right), \\
& \varepsilon_{x y}=-\varepsilon_{y x}=\frac{-i \omega_{p}^{2}}{2 \omega^{2}}\left(\frac{\omega}{\omega+\Omega}+\frac{R}{\Delta 21 / 2} z\right), \\
& \varepsilon_{x x}=\varepsilon_{z x}=\frac{-\omega_{p}^{2}}{4 \pi \omega} \frac{n_{x}}{n_{z}} z^{\prime}, \\
& F_{y z}=-F_{z y}=i \varepsilon_{x z}, \\
& \varepsilon_{z z}=1-\frac{\omega_{p}^{2}}{\omega^{2}}\left(1+\frac{\omega^{2}}{4 \Omega^{2}} \frac{n_{x}^{2}}{n_{z}^{2}} \frac{x}{R} z^{\prime}\right) .
\end{aligned}
$$

'I'he disperston functions $Z$ and $Z$ ' are never larger than 1 , and for standard tokamaks $\omega_{\mathrm{p}}^{2} / \Omega^{2} \sim 1$. Near resonance the components $\varepsilon_{\mathrm{xx}}$ and $\varepsilon_{\mathrm{xy}}$ are large (of order $R / \Delta$ ), while the other components are of order one. As discussed in Sec. II, the electric fields change smoothly through cyclotron resonance, while $E^{-}-E_{x}-i E_{y}$ becomes small, of order $1 / c_{x x} \simeq \Delta / \mathrm{h}$. The criterion that this effect be negligible is that $\varepsilon_{x x} \cong 1$ or, in general, 


$$
\omega_{\mathrm{p}}^{2} / \Omega^{2} \ll 2^{3 / 2} \Delta / \mathrm{R}=2^{3 / 2} \mathrm{n}_{\mathrm{z}}\left(\mathrm{T} / \mathrm{mc^{2 }}\right)^{1 / 2}
$$

which defines a "low density" plasma for cyclotron heating. For perpendicular propagation the resonance broadening depends on collisions rather than on the Doppler shift; however, a finite microwave source produces a broad spectrum in $\mathrm{n}_{z}$ and the Doppler broadening dominates. With an average $n_{z}=0.5, T=1 \mathrm{keV}$, and $B=20 \mathrm{kG}$, the dispersion can be neglected for $\mathrm{n} \ll 2.5 \times 10^{12} \mathrm{~cm}^{-3}$.

Some mirror plasmas with cyclotron heating" are "low density" by this criterion, but the high density approximation, in which $\omega_{\mathrm{p}} \cong \Omega$ and $\mathrm{R} / \Delta>>$ 1 , is necessary for tokamaks.

A. The heating rate

$$
\begin{aligned}
& \text { From Eq. (1), one finds } \\
& E_{z}=-\left[\left(\varepsilon_{x z}+n_{x} n_{z}\right) E^{-}+\text {in } n_{x} E_{y}\right] /\left(\varepsilon_{z z}-n_{x}^{2}\right)
\end{aligned}
$$

and

$$
E^{-}=-i\left[\left(\varepsilon_{x x}-i \varepsilon_{x y}-n_{z}^{2}\right) E_{y}-i\left(\varepsilon_{x z}+n_{x z} n_{z}\right) E_{z}\right] /\left(\varepsilon_{x x}-n_{z}^{2}\right) \cdot
$$

Because $\varepsilon_{\mathrm{xx}}-1 \varepsilon_{\mathrm{xy}}$ is of order one and $\varepsilon_{\mathrm{xx}}$ is of order $\mathrm{R} / \Delta, \mathrm{E}^{-}$is smaller than $E_{y}$ or $E_{z}$ by a factor $\Delta / R ; E$ may be neglected in $E q .(14)$, and

$$
\begin{aligned}
E^{-} & +\frac{n_{x}}{n_{z}} \frac{x}{R} E_{z} \cong-i E_{y}\left[\left(\varepsilon_{x x}-i \varepsilon_{x y}-n_{z}^{2}\right)\right. \\
& \left.-\frac{n_{x} n_{z}\left(\varepsilon_{x z}+n_{x} n_{z}\right)}{\left(\varepsilon_{z z}-n_{x}^{2}\right)}+n_{x}^{2} \frac{x}{R} \frac{\left(\varepsilon_{x x}-n_{z}^{2}\right)}{\left(\varepsilon_{z z}-n_{x}^{2}\right)}\right] /\left(\varepsilon_{x x}-n_{z}^{2}\right)
\end{aligned}
$$

Because $Z^{\prime}(\xi)=-2 \cdot[1+\xi Z(\xi)]$, one finds $n_{x}^{2} \varepsilon_{x x} x / R-n_{x} n_{z} \varepsilon_{x z} \stackrel{\cong}{=}-n_{x}^{2} \omega_{p}^{2} / 2 \omega^{2}$, where terms of order $\Delta / R$ are neglected. The only large term is in the denominator, so to order $\Delta / R$ one has 


$$
E^{-}+\frac{n_{x}}{n_{z}} \frac{x}{R} E_{z}=\frac{-1 E y^{3 / 2} \Delta\left[\left(1-\alpha / 2-n_{z}^{2}\right)(1-\alpha)-n_{x}^{2}\right]}{\alpha R Z}
$$

where $\alpha=\omega_{\mathrm{p}}^{2} / \omega^{2}=\omega_{\mathrm{p}}^{2} / \Omega^{2}$. Because

$$
\operatorname{Im}\left[1 / Z\left(x / \Delta 2^{1 / 2}\right)\right]=\frac{-\pi^{1 / 2} \exp \left(-x^{2} / 2 \Delta^{2}\right)}{\mid Z\left(x /\left.\Delta \sqrt{2}\right|^{2}\right.}
$$

the perpendicular heating rate of Eq. (9) is

$$
\frac{d^{2} W_{1}}{d t d V}=\sum_{\operatorname{modes}} \frac{m}{4 \pi \alpha} \frac{2^{l / 2} \Delta}{R}\left|t_{y}^{\prime}\right|^{2}\left[\frac{\left(1-\alpha / 2-n_{z}^{2}\right)(1-\alpha)-n_{x}^{2}}{1-\alpha-n_{x}^{2}}\right]^{2} \operatorname{Im}(1 / Z) \text {. }
$$

The perpendicular index of refraction near resonance is

$$
n_{x}^{2}=\left\{3-2 \alpha-n_{z}^{2} \pm\left[\left(1+n_{z}^{2}\right)^{2}-4 \alpha n_{z}^{2}\right] 1 / 2\right\} / 2
$$

to lowest order and is real. The \pm sign refers to the $X(+)$ or $0(-)$ mode.

The heating rate of Eq. (19) is the principal result of this calculation. The shape of the resonance line is Illuslraled lil Fly. $G$, in wilith $\operatorname{Im}(Z)$ is plotted for low density plasmas and $\operatorname{Im}(1 / Z)$ for high density plasmas. The magnitude and width of the two functions are similar, and absorption occurs within a distance of order $\Delta$ from resonance.

B. Wave attenuation

For an energy flux $\vec{S}$ in a plane plasma, one has

$$
\nabla \cdot \vec{S}=\frac{\partial S}{\partial x}=-\frac{d^{2} W}{d t d V}
$$




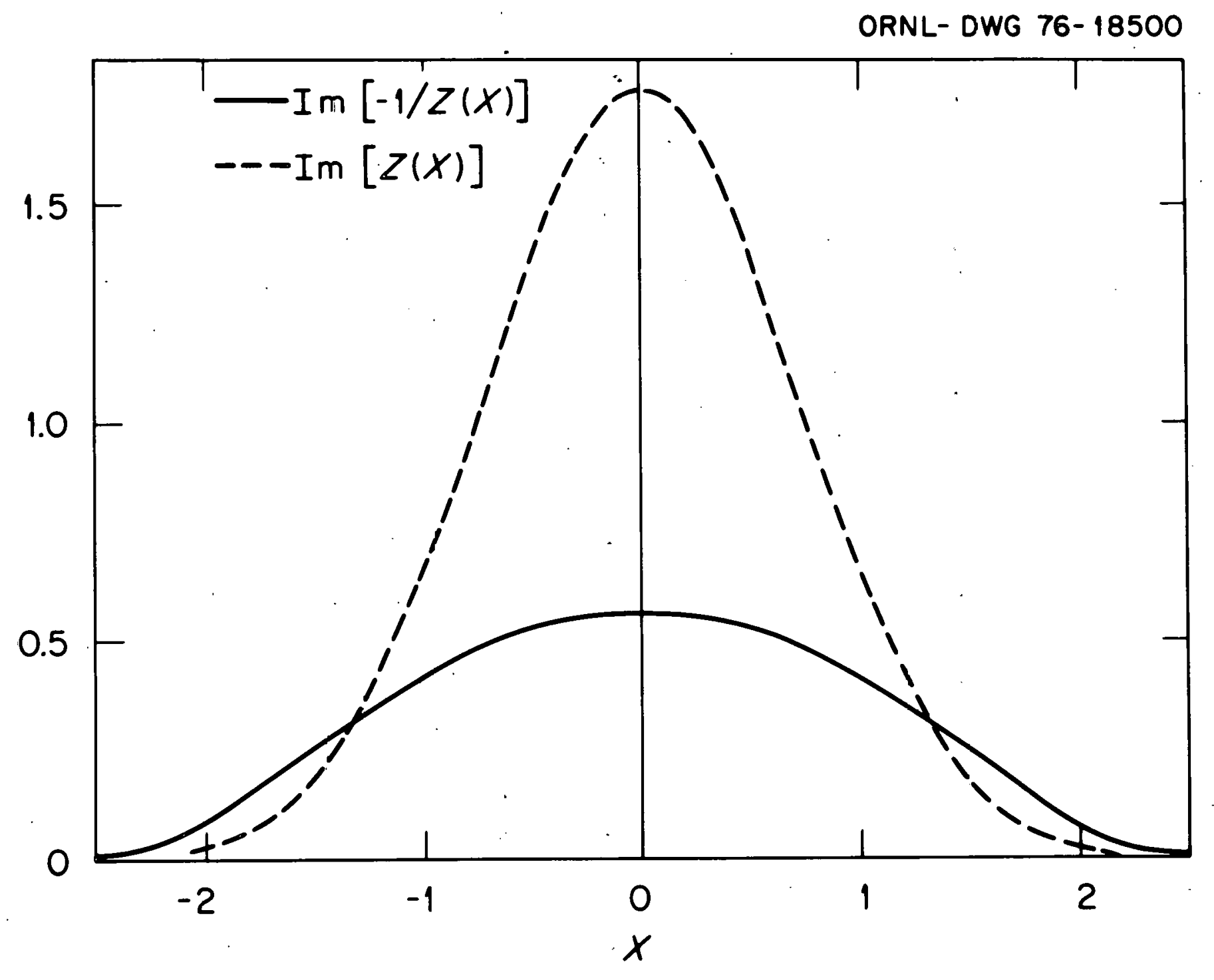

เ

Fig. 6 . 
where

$$
\begin{aligned}
S_{x} & =\frac{C}{8 \pi} \operatorname{Re}\left(\vec{E} \times \vec{B} *+\frac{1}{2} \vec{E} * \cdot \frac{\overrightarrow{\partial E}}{\partial n} \cdot \frac{\vec{E}}{\partial x}\right. \\
& \cong \sum_{\text {modes }} \frac{C}{8 \pi} n_{x}\left|E_{y}\right|^{2}\left[1+\frac{(1-\alpha) n_{z}^{2}}{\left(1-\alpha-n_{x}^{2}\right)^{2}}\right]
\end{aligned}
$$

near resonance.

By assuming that the energy associated with each wave vector is conserved, one finds for real $\vec{k}$

$$
\begin{aligned}
\frac{1}{S_{x}(x, \vec{k})} \frac{\partial S_{x}(x, \vec{k})}{\partial x} & =\frac{2 \omega}{c} \frac{2^{1 / 2} \Delta}{R} \frac{1}{\alpha n_{x}} \operatorname{Im}(1 / \bar{z}) \\
& \times \frac{\left[\left(1-\alpha / 2-n_{z}^{2}\right)(1-\alpha)-n_{x}^{2}\right]^{2}}{\left[\left(1-\alpha-n_{x}^{2}\right)^{2}+(1-\alpha) n_{z}^{2}\right]} .
\end{aligned}
$$

This expression is equivalent to the imaginary part of $-2 k_{x}$ in a wave damping rreatment.

For the representation with total index of refraction $n$ and angle $\theta$, so that $\mathrm{n}_{\mathbf{x}}=\mathrm{n} \sin \theta$ and $\mathrm{n}_{z}=\mathrm{n} \cos \theta$, one finds

$$
\operatorname{Im}(n)=\left(2 \pi T / m c^{2}\right)^{1 / 2} \frac{\exp \left(-x^{2} / 2 \Delta^{2}\right)}{|z|^{2}} \frac{\cos \theta}{\alpha} \frac{M^{2}}{P Q},
$$

with

$$
\begin{aligned}
& M=(1-\alpha)\left(1-\alpha / 2-n^{2} \cos ^{2} \theta\right)-n^{2} \sin ^{2} \theta, \\
& P=n^{2} \sin ^{2} \theta+\alpha-1,
\end{aligned}
$$

and $Q=2 n^{2} \sin ^{2} \theta+2 \alpha-2-\sin ^{2} \theta$.

For easy comparison with the results of Akhiezer ${ }^{14}$ and Litvak, ${ }^{15}$ this result can be laboriously transformed by using the dispersion relation. One finds 


$$
\begin{aligned}
\frac{M^{2}}{P} & =n^{4}\left(1-\alpha+\frac{7 \alpha \sin ^{2} \theta}{4}\right) \\
& -n^{2}\left[(1-\alpha)\left(1-\frac{\alpha}{4}\right)\left(1+\cos ^{2} \theta\right)\right. \\
& +(1+\alpha)\left(1-\frac{\alpha}{2}\right) \sin ^{2} \theta \\
& \left.-\frac{\alpha^{2}}{4}\left(1+\cos ^{2} \theta\right) \tan ^{2} \theta\right] \\
& +(1-\alpha)\left(1-\frac{\alpha}{2}\right)-\frac{\alpha^{2}}{4}(2-\alpha) \tan ^{2} \theta .
\end{aligned}
$$

By contour integration one finds

$$
\int_{-\infty}^{\infty} \mathrm{dx} \operatorname{Im}\left[1 / Z\left(x / \Delta 2^{1 / 2}\right)\right]=-\pi \Delta 2^{-1 / 2}
$$

Because $Z$ has no zeros in the upper half of the complex plane, the . integral is converted to an integral over a large half circle in the upper half plane. Along this contour, the first two terms of the large argument expansion give this result. Whenever the line width $\Delta$ is small compared to the size of the plasma, the fraction of the energy absorbed as a ray passes through the resonant surface in the high density limit is

$$
\begin{aligned}
f & =1-\exp \left\{-\frac{(2 \pi)^{2}}{\alpha} \frac{R}{\lambda} \frac{n_{z}^{2}}{n_{x}} \frac{T}{m c^{2}}\right. \\
& \left.\times \frac{\left[\left(1-\alpha / 2-n_{z}^{2}\right)(1-\alpha)-n_{x}^{2}\right]^{2}}{\left[\left(1-\alpha-n_{x}^{2}\right)^{2}+(1-\alpha) n_{z}^{2}\right]}\right\},
\end{aligned}
$$

where $\lambda$ is the wavelength. The damping coefficient is proportional to the temperature and to the major radius of the torus, as expected. The density dependence is not easy to untangle and is discussed in Sec. V.

The damping rate of Eqs. (24) and (26) is identical to the results of Akhiezer, ${ }^{14}$ Litvak, 15 Stepanov, 16 and Alikaev ${ }^{17}$ (except for some minor 
misprints in these references); the form of Eqs. (23) and (28) is more convenient for calculations. The heating rate of Eq. (19) may also be obtained from the conductivity tensor.

\section{RESULTS AND CONCLUSIONS}

\section{A. Almost perpendicular incidence}

The result of $\mathrm{Eq}$. (28) is particularly advantageous in evaluating limiting cases. Near perpendicular incidence, for smail $n_{z}$, one finds the fraction of energy absorbed from the $X$ mode to be

$$
\mathrm{f}_{\mathrm{x}} \stackrel{\cong}{=}-\exp \left[-\pi^{2} \frac{\mathrm{T}}{\mathrm{m} \mathrm{c}^{2}} \frac{\mathrm{R}}{\lambda} \mathrm{n}_{\mathrm{z}}^{2} \frac{(2-\alpha)^{2}(1+\alpha)^{2}}{\alpha(2-\alpha) 1 / 2}\right] \text {, }
$$

so that $\mathrm{f}_{\mathrm{x}}$ is zero for $\mathrm{n}_{\mathrm{z}}=0$, but rapidly increases to unity for finite $\mathrm{n}_{z}$. In the same limit, for the 0 mode

$$
\Gamma_{0} \simeq 1-\operatorname{esp}\left[\begin{array}{cccc}
-n^{2} & \mathrm{~T} & \mathrm{R} & \alpha(1-\alpha)^{1 / 2} \\
& \mathrm{mc}^{2} & \frac{\alpha(1-\alpha)}{1+\mathrm{n}^{2}\left(1^{-}-\alpha\right)}
\end{array}\right]
$$

which is maximum at perpendicular incidence. Although these formulas are valid only for a high density plasma, in the range $1>\alpha>\mathrm{n}_{z}\left(\mathrm{~T} / \mathrm{mc}^{2}\right)^{1 / 2}$ the density dependence is approximately correct.

B. Fractional absorption

The fractional absorption of the $\mathrm{X}$ mode, plotted as a function of $\mathrm{n}_{z}$ for several values of density at resonance, is shown in Fig. 7. The absorption at low densities is complete except for a region near perpendicular propagation. For higher densities, the absorption is only complete for large $\mathrm{n}_{z}$, indicating that a slow wave structurc that would radiate in the $n_{z}>1$ region would be advantageous. In any case, for $\omega_{\text {po }}^{2}>\omega^{2}$ the absorption becomes small. A similar plot for the 0 mode is given in Fig. 


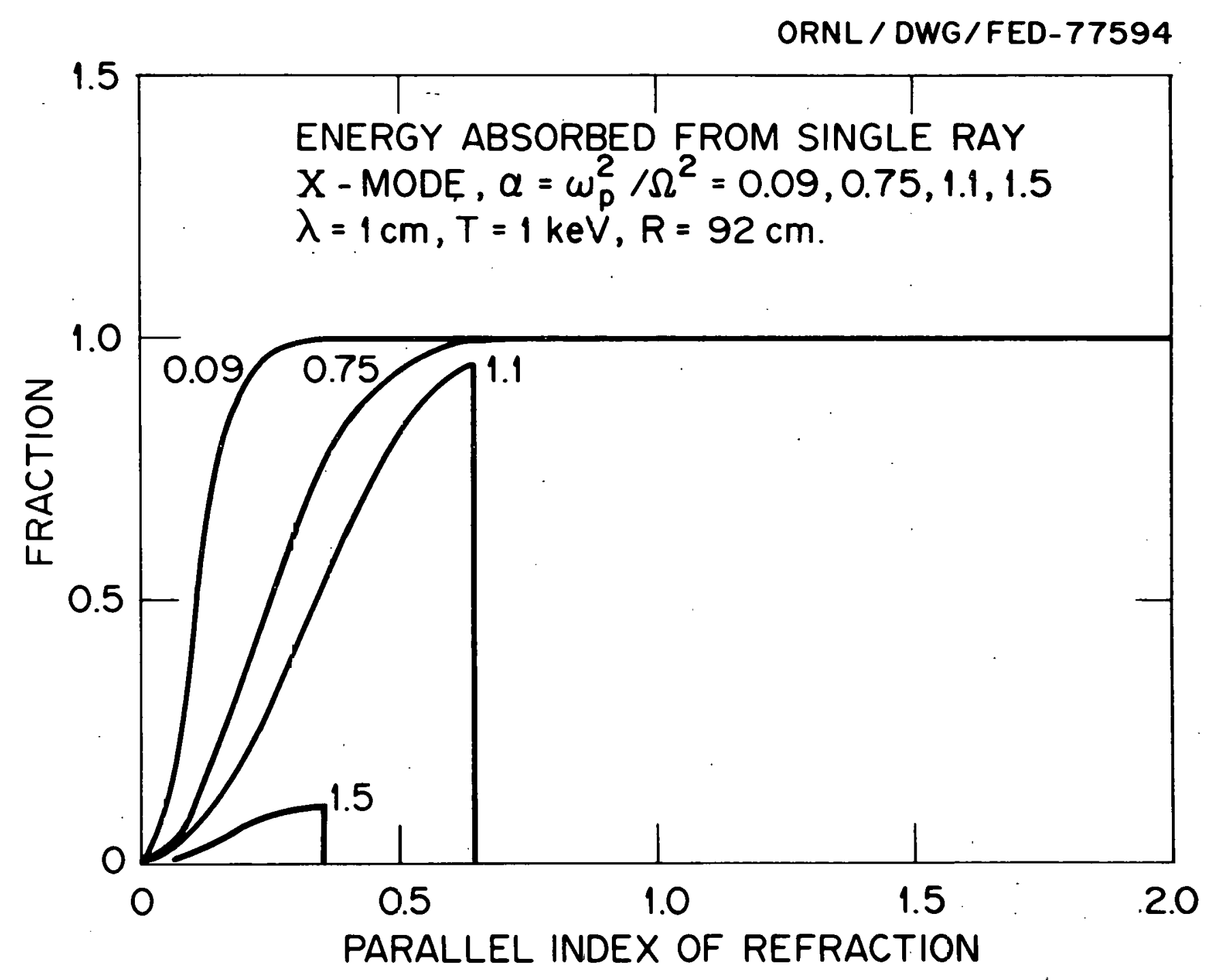

Fig. 7 . 
8. Here one sees that the absorption increases with density and is confined to the region where $\mathfrak{n}_{z}<1$. A narrow beam near perpendicular incidence is most efficient for this mode. These plots are for a tokamak with $R / \lambda=92$. For larger major radius and higher frequencies, the damping decrement increases.

C. Waveguide excitation

The simplest, but not the optimum, method of launching the waves is a waveguide aperture opening into the plasma. For a rectangular waveguide of width $a$ and breadth $b$, the $X$ mode is excited preferentially with the long side mounted parallel to the toroidal field. For a cosine dependence of the electric field $E_{y}$, the normalized spectrum in $n_{z}$ is

$$
U_{x}\left(n_{z}\right)=\frac{\lambda^{3}}{2 \pi^{2} a^{3}} \frac{\cos ^{2}\left(\pi a a_{z} / \lambda\right)}{\left[n_{z}^{2}-(\lambda / 2 a)^{2}\right]^{2}} \text {. }
$$

Fur lie 0 tiude, the gulde ls urlented with the short side along the fleld. For a uniform electric field $E_{2}$ the spectrum is

$$
U_{0}\left(n_{z}\right)=\frac{\lambda}{\pi^{2} b} \frac{\sin ^{2}\left(\pi b n_{z} / \lambda\right)}{n_{z}^{2}} .
$$

The fractional absorption for these spectra, with $a=\lambda / 2, b=\lambda / 4$, $\lambda=1 \mathrm{~cm}$, and $\mathrm{R}=92 \mathrm{~cm}$, is plotted in Fig. 9 as a function of density at the resonant surface. One sees that the $\mathrm{X}$ mode is more effective, with $90 \%$ of the energy absorbed at low density. The missing fraction is the small $\mathrm{n}_{z}$ part of the spectrum. There is essentially no absorption for $\omega_{p o}^{2}>\omega^{2}$, although the $x$ wave can propagate to twice this density.

The absorption of the 0 mode is smaller but sufficient for practical purposes, because the wave is reflected from the metallic walls and will 


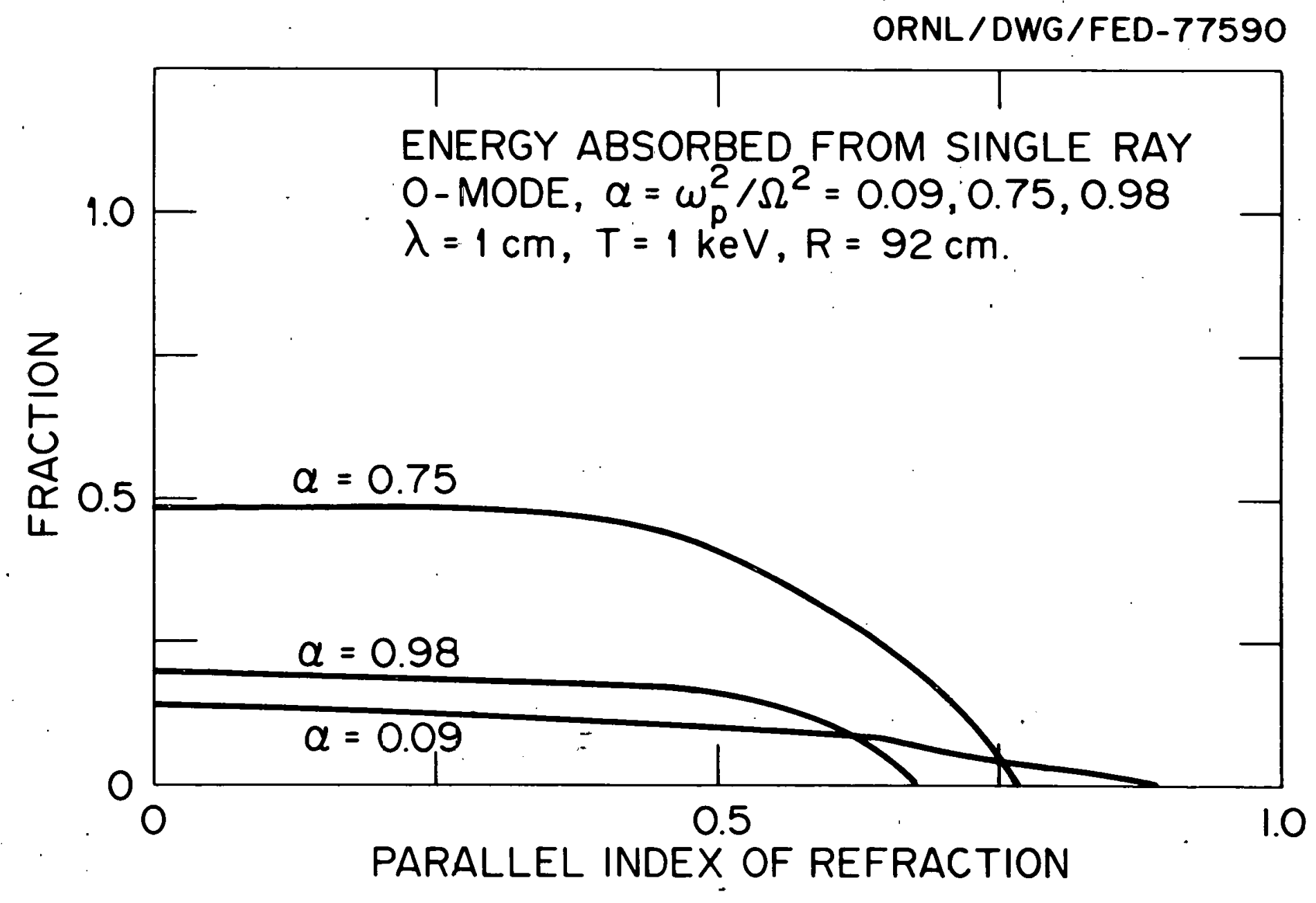

Fig. 8 . 
ORNL / DWG / FED-77589

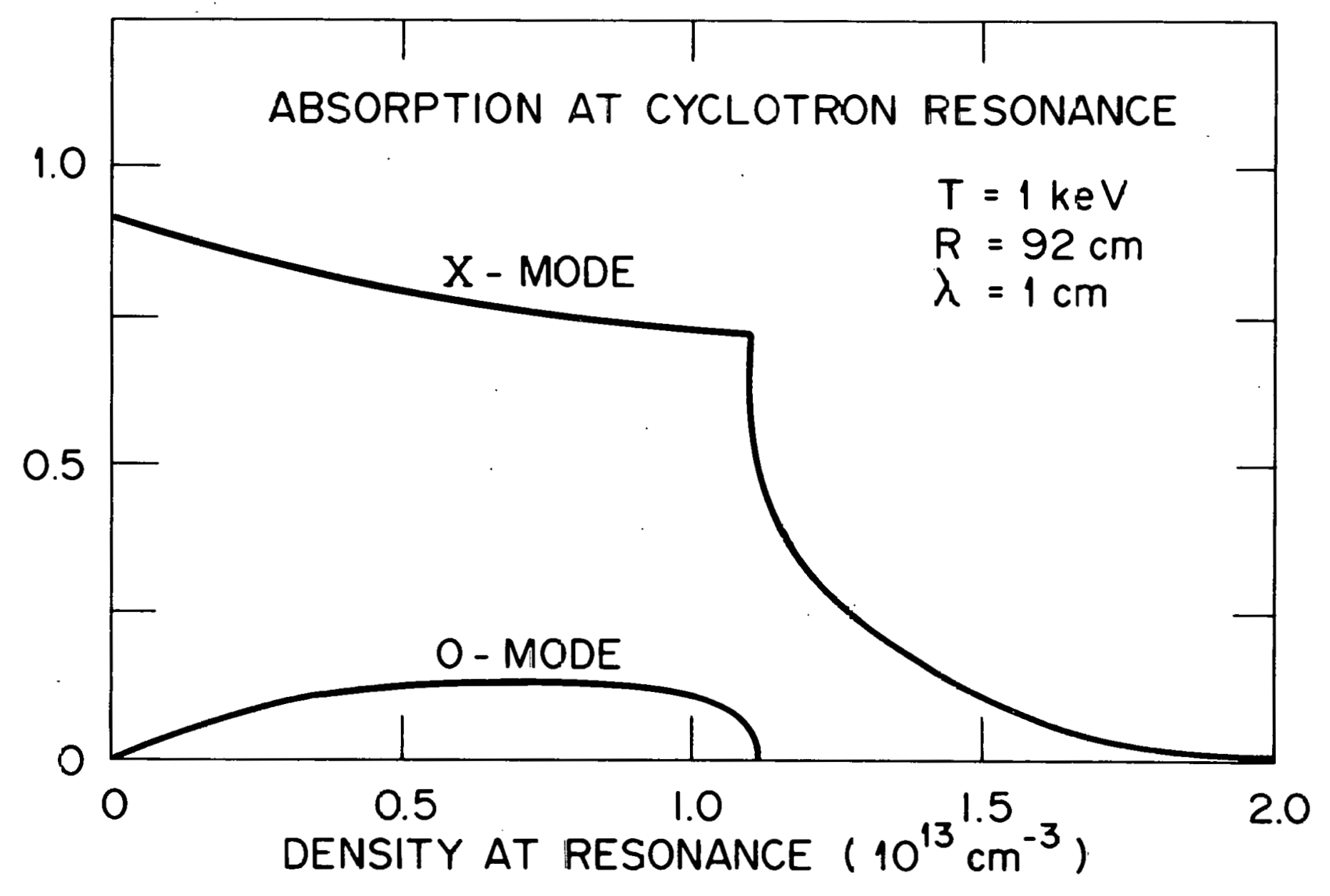

Fig. 9. 
agaln pass through the resonant surface. In one sense the 0 mode offers an advantage, because the absorption 18 small at low densities, near the edge of the plasma. A simple waveguide aperture is certainly not the optimum way to launch the 0 mode. The small magnitude of the total absorption is primarily an artifact of the broad spectrum in $n_{z}$ that this aperture produces.

D. Spatial dependence

The absorption occurs near the resonant zone in this treatment. For large $x / \Delta$ one has

$$
-\operatorname{Im}\left[1 / 2\left(x / \Delta 2^{1 / 2}\right)\right] \cong \pi^{1 / 2} \frac{x^{2}}{2 \Delta^{2}} \exp \left(-x^{2} / 2 \Delta^{2}\right)
$$

For $x / \Delta=5$ one finds this function is $5 \times 10^{-5}$ of its value at $x=0$. From Eq. (23), with the minimum value of $\alpha=8^{1 / 2} \Delta / R$ corresponding to maximum absorption, one finds that the incident energy is decreasing as $\exp \left[-5(10)^{-4}\left(1+n_{z}^{2}\right) x / \lambda\right]$, which is completely negligible. For $R=1 \mathrm{~m}$ and $\mathrm{T}=1 \mathrm{keV}$ this point is $11 \mathrm{~cm}$ from resonance with $\Delta$ proportional to $\mathrm{T}^{\mathrm{l} / 2} \mathrm{R}$. One concludes that cyclotron heating is well localized.

E. Conclusions

The most serious problem in cyclotron heating of tokamaks is the density limitation. Whenever the central density is high enough that $\omega_{\text {po }}^{2}>$ $\omega^{2}$, the wave energy will be deposited along the resonant surface near the wall, with potentially deleterious effects. The only cold plasma mode that propagates in the region $\alpha=\omega_{\mathrm{p}}^{2} / \Omega^{2}>2$ is the whistler or helicon, and it will not propagate to cyclotron resonance. Finite temperature effects do not change the characteristics of the whistler very much. Because this mode propagates almost along field lines, it is extremely 
difficult to launch in a tokamak. One concludes that electron cyclotron heating is probably not possible for $\omega_{p}^{2} / \Omega^{2}>2$, and the practical limit is $\omega_{\mathrm{p}}^{2} / \Omega^{2} \cong 1$. Heating at cyclotron harmonics has an even lower density limit. Heating of electrons by parametric oscillations is also difficult in this high density regime, because the pump wave must first propagate with the plasma.

For moderate density plasmas, the experimental results with tokamaks ${ }^{2}$ are in agreement with the theoretical results of the present paper. Heating occurs at cyclotron resonance, increasing the temperature of all the electrons without preferential heating of high energy electrons, and a large fraction of the incident energy is absorbed. From Eq. (28) we predict the heating rate of both modes to be directly proportional to electron temperature, to the major radius of the torus, and to the microwave frequency. There is no positive confirmation of these dependences, but there is some negative evidence. Experiments on the Spherator device ${ }^{3,18}$ indicate a nonlinear interaction at the upper hybrid resonance. The electron temperature was very low, so that the linear heating was sma11. Furthermore, with low temperature the linear turning point ${ }^{19}$ for the $\mathrm{X}$ mode occurs very close to the upper hybrid resonance, so that the electric fields become very large and can exceed the threshold for parametric excitation. In a tokamak with ohmic heating, the electron temperature is always large enough for efficient linear heating, and the $\mathrm{X}$ mode is turned back well before the upper hybrid resonance.

In addition to the bulk heating of a tokamak plasma with microwaves, which has a direct effect on the transport coefficients of the plasma, the spatial localization of cyclotron heating makes it possible to modify the 
temperature profile of the plasma. This profile control is of particular interest as a means of optimizing the transport coefficients. An experiment is being planned at the Oak Ridge National Laboratory to test the results of this calculation, the effects of bulk heating, and the effects of local changes on the temperature profile of a tokamak plasma.

\section{ACKNOWLEDGMENT}

The authors gratefully acknowledge the help and criticism of D. B. Batchelor and J. B. Wilgen.

This research was sponsored by the Department of Energy under contract with Union Carbide Corporation at Oak Ridge National Laboratory and under Contract AT-(40-1) -2598 at the University of Tennessee. 


\section{REFERENCES}

IV. V. Alikaev, G. A. Bobrovski1, M. M. Ofitserov, V. I. Poznyak, and K. A. Razumova, Zh. Eksp. Teor. Fiz. P1s'ma Red. 15, 41 (1972) [JETP Lett. 15, 27 (1972)] .

${ }^{2}$ V. V. Allkaev, G. A. Bobrovski1, V. I. Poznyak, K. A. Razumova, V. V. Santkov, Y. A. Sokolov, and A. A. Shmarin, F1z. Plazmy 2, 390 (1976) [Sov. J. Plasma Phys. 2, 212 (1976)].

${ }^{3}$ M. Okabayashi, K. Chen, and M. Porkolab, Phys. Rev. Lett. 31, 1113 (1973).

${ }^{4}$ R. A. Dandl, A. C. England, W. B. Ard, H. O. Eason, M. C. Becker, and G. M. Hass, Nucl. Fusion 4, 344 (1964).

5R. A. Dandl, J. L. Dunlap, H. O. Eason, P. H. Edmonds, W. T. Herrmann, and N. H. Lazar, in Plasma Physics and Controlled Nuclear Fusion Research (International Atomic Energy Agency, Vienna, 1969), Vo1. 2, p. 435 .

${ }^{6}$ C. L. Hedrick, R. A. Daudl, J. A. Colble, R. A. Dory, H, O. Eason, E. G. Harris, G. R. Haste, H. Ikegami, E. F. Jaeger, N. H. Lazar, D. H. NcNeil, D. G. McAlees, D. B. Nelson, L. W. Owen, D. A. Spong, and N. A. Uckan in Plasma Physics and Controlled Nuclear Fusion Research (International Atomic Energy Agency, Vienna, 1977), Vol. 2, p. 145.

7J. C. Sprott, Phys. Fluids 14, 1795 (1971).

${ }^{8}$ 0. C. Eldridge, Phys. Fluids 15,676 (1972).

${ }^{9}$ See, for example, W. P. Allis, S. J. Buchsbaum, and A. Bers, Waves in Anisotropic Plasma (Massachusetts Institute of Technology Press, Cambridge, Mass., 1963). 
10T. H. Stix, Phys. Fluids 3 , 19 (1960).

${ }^{1} 1_{D}$. B. Batchelor (private communication).

${ }^{12}$ C. F. Kennel and F. Engelmann, Phys. Fluids 9, 2377 (1966).

${ }^{13}$ B. D. Frled and S. Conte, The Plasma Dispersion Function (Academic Press, New York, 1961).

${ }^{14}$ A. I. Akhiezer, I. A. Akhiezer, R. V. Polovin, A. G. Sitenko, and K. N. Stepanov, Plasma Electrodynamics (Pergamon Press, Oxford, 1975), Vo1. I.

15A. G. Litvak, G. V. Permitin, E. V. Suvorov, and A. A. Frajman, Nucl. Fusion 17, 659 (1977).

16 Wave damping in a high density plasma was first discussed by K. N. Stepanov and V. I. Pakhomor, Zh. Eksp. Teor. Fiz. 38, 1564 (1960) [Sov.Phys.-JETP 11, 1126 (1960)] .

17 Damping in high density tokamaks is calculated by V. V. Alikaev, Yu. N. Dnestrovsky, V. V. Parai1, and G. V. Perevezev, Fiz. Plazmy [Sov. J. Plasma Phys.] 3, 230 (1977).

${ }^{18}$ Parametric excitation in a small torus with low electron temperature was reported by A. I. Anisimov, N. I. Vinogradov, and B. P. Poloskin, 7.h. Terh. Phys. 43, 727 (1973) [Sov. Phys,-Tech. Phys. 20, 629 (1976)] .

${ }^{19}$ T. H. Stix, Phys. Rev. Lett. 15, 878 (1965). 
FIGURE LEGENDS

Fig. 1. The CMA diagram for a cold electron plasma with Infinite mass 1ons.

Fig. 2. The cross section of a tokamak, showing the locations of the cyclotron surface, the upper hybrid layer, and the $\mathrm{X}$ mode cutoff.

Fig. 3. The electric fields $E_{x}, i E_{y}, E_{z}$ in $100 \mathrm{~V} / \mathrm{cm}$ for an energy flux of $100 \mathrm{~W} / \mathrm{cm}^{2}$ and $\mathrm{n}_{\mathrm{x}}$ in dimensionless untts. The electron dembily profile is parabolic with central density less than critical; $\mathfrak{n}_{0}=8 \times$ $10^{12} \mathrm{~cm}^{-3}, B_{0}=10.7 \mathrm{kG}$.

Fig. 4. The ray trajectories in the principal plane of the torus for the $X$ mode launched from the inside with $\omega_{\text {po }}^{2}<\omega^{2}$. starting frum the left $n_{z}=-1.0,-0.75,-0.5,0.5,0.75$, and 1.0 , respectively.

Fig. 5. The ray trajectories with $\omega_{\text {po }}^{2}>\omega^{2}$. Starting from the left $n_{z}=-0.75,-0.5,-0.25,0.25,0.5$, and 0.75 , respectively.

Fig. 6. The spatial form factors for wave damping in dimensionless units.

Fig. 7. Energy absorbed from a single ray as a function of $n_{z}$ tor several values of density, $X$ mode.

Fig. 8. Energy absotled from a single ray as a function of $\mathrm{n}_{\mathrm{z}}$ fur several values of density, 0 mode.

Fig. 9. Fraction of energy absorbed at cyclotron resonance, integrated over a waveguide spectrum, plotted as a function of density. 
ORNL/TM-6052

INTERNAL DISTRIBUTION

1. D. B. Batchelor
2. L. A. Berry
3. C. E. Bush
4. J. D. Callen
5. R. A. Dand1
6. R. A. Dory
7. H. O. Eason
8-14. O. C. Eldridge
15. A. C. England
16. S. Hiroe
17. H. C. Howe
18. E. F. Jaeger
19. G. G. Kelley
20. N. H. Lazar
21. O. B. Morgan
22. M. Murakam1

\author{
23. W. Namkung \\ 24. G. H. Neilson \\ 25. Y-K. M. Peng \\ 26. B. H. Quon \\ 27. M. W. Rosenthal \\ 28. D. A. Spong \\ 29. N. A. Uckan \\ 30. J. B. W1lgen \\ 31-32. Centra1 Research Library \\ 33. Document Reference Section \\ 34-35. Fusion Energy Division Library \\ 36. Fusion Energy Diviston Reports \\ Office \\ 37-42. Laboratory Records Department \\ 43. Laboratory Records - ORNL-RC \\ 44. Patent office
}

\section{EXTERNAL DISTRIBUTION}

45. I. Alexeff, Department of Electrical Engineering, University of Tennessee, Knoxville, TN 37916

46. V. V. Alikaev, I. V. Kurchatov Institute of Atomic Energy, Moscow, U.S.S.R.

47. Prof. Piero Caldirola, Laboratorio di Fisica del Plasma ed Elettronica Quantistica del C.N.R., Via Celoria, 16, 20133 Milano, Italy

48. Centre de Recherches en Physique des Plasmas, 21 Avenue des Bains, 1007, Lausanne, Switzerland

49. T. Consol1, Centre d'Etudes Nucleaires de Grenoble, Avenue des Martyrs-38-Grenoble, France

50. J. Cordey, Culham Laboratory, UK Atomic Energy Authority, Abingdon, Oxon, OX14 3DB, England

51. N. A. Davies, Division of Magnetic Fusion Energy, Department of Energy, Washington, DC 20545

52. S. 0. Dean, Division of Magnetic Fusion Energy, Department of Energy, Washington, DC 20545

53. A. M. Dupas, Documentation S.I.G.N., Départment de la Physique du Plasma et de la Fusion Controlée, Association Euratom-CEA sur la Fusion, Centre d'Etudes Nucleaires, BP 85 Centre du Tri, 38041 Grenoble, France

54. T. Fidone, Départment de 1 a Physique du Plasma et de la Fusion Controlée, B.P. No. 6, 92260 Fontenay-aux-Roses, France

55. H. K. Forsen, Exxon Nuclear Company, Inc., 777 106th Avenue NE, Bellevue, WA 98004

56. M. Fujiwara, Institute of Plasma Physics, Nagoya University, Nagoya, Japan 
57. H. P. Furth, Plasma Physics Laboratory, Princeton University, Princeton, NJ 08540

58. G. E. Guest, General Atomic Company, P.0. Box 81608, San Diego, CA 92138

59. V. E. Golant, Ioffee Institute, Leningrad, U.S.S.R.

60. R. W. Gould, Professor of Electrical Englneering and Physics, Bldg. 116-81, California Institute of Technology, Pasadena, CA 91109

61. Harold Grad, Courant Institute, New York University, 251 Mercer Street, New York, NY 10012

62. I. Gverdsiteli, Physico-Technical Institute, Georgian Academy of Sciences, Sukhumi, U.S.S.R.

63. A. M. Hamende, International Centre for Theoretical Physics, Trieste, Italy

64. E. G. Harris, Department of Physics, University of Tennessee, Knoxville, TN 37916

65. A. Hasegawa, Bell Laboratories, 600 Mountain Ave., Murray Hill, NJ 07974

66. Research Laboratory of Electronics, Document Room 36-412, Aeen: $\mathrm{J}$. Hewitt, Massachusetts Institute of Technology, Cambridge, MA 02139

67. Dr. Toru Hiraoka, Japan Atomic Energy Research Institute, Tokai, Ibaraki, Japan

68. A. Hirose, Physics Department, University of Saskatchewan, Saskatchewan, Canada

69. W. M. Hooke, Plasma Physics Laboratory, Princeton University, Princeton, NJ 08540

70. H. C. S. Hsuan, Plasma Physics Laboratory, Princeton University, Princeton, N.T nR54n

71. P. Hubert, Service de Recherches sur la Fusion Controlëe, Centre d'Etudes Nucleaires, Fontenay-aux-Roses (Seine), France

72. H. Ikegami, Nagoya University, Nagoya, Japan

73. E. E. Kintner, Division of Magnetic Fusion Energy, Department of Energy, Washington, DC 20545

74. H. E. Knoepfel, Laboratorio Gas Ionizzati, C.P. 65, 00044 Frascat1 (Roma), Italy

75. N. A. Krall, Laboratory for Applied Plasma Studies, Science Appl1cations, Inc., La Jolla, CA 92037

76. A. H. Kritz, Department of Physics, Hunter College, New York, NY 10021

77. H. H. Kuehl, Department of Electrical Engineering, University of Southern California, Los Angeles, CA 90007

78. Librarian, Institute for Plasma Physics, 8046 Garching bei München, Federal Republic of Germany

79. Librarian, Culham Laboratory, UK Atomic Energy Authority, Abingdon, Oxon 0X14 3DB, England

80. A. J. Litchenburg, Department of Electrical Engineering and Computer Sciences, University of California, Berkeley, CA 94720

81. A. G. Litvale, Radiophysical Research Institute, Gor'kij, U.S.S.R.

82. Plasma Physics Library, Plasma Physics Laboratory, Princeton University, P.0. Box 451, Princeton, NJ 08540

83. T. Ohkawa, General Atomic Company, P.0. Box 81608, San Diego, CA 92138 
84. R. R. Parker, Research Laboratory of Electronics, Massachusetts Institute of Technology, Cambridge, MA 02139

85. F. W. Perkins, Plasma Physics Laboratory, Princeton University, Princeton, NJ 08540

86. Plasma Laboratory Reading Room, Rm. 20A-222, Massachusetts Institute of Technology, Cambridge, MA 02139

87. M. Porkolab, Rm. 36-213, Massachusetts Institute of Technology, Cambridge, MA 02139

88. M. S. Rabinovich, Lebedev Institute of Physics, Academy of Sciences of the U.S.S.R., Leninsky Prospect 53, Moscow, U.S.S.R.

89. H. Dreicer, Los Alamos Scientific Laboratory, P.0. Box 1663, Los Alamos, NM 87544

90. D. J. Rose, Massachusetts Institute of Technology, Cambridge, MA 02139

91. J. L. Shohet, Department of Electrical Engineering, University of Wisconsin, WI 53706

92. J. C. Sprott, Physics Department, University of Wisconsin, Madison, Madison, WI 53706

93. T. H. Stix, Plasma Physics Laboratory, Princeton University, Princeton, NJ 08540

94. Eugene Velikov, Thermonuclear Laboratory, Kurchatov Institute of Atomic Energy, 46 Ulitsa Kurchatova, Post Box 3402, Moscow, U.S.S.R.

95. H. Woodson, University of Texas, Austin, TX 78712

96. Director, Research and Technical Support Division, Oak Ridge Operations, Department of Energy, P.O. Box E, Oak Ridge, TN 37830

97-123. Technical Information Center, P.0. Box 62, Oak Ridge, TN 37830 